Originales

\title{
La actividad de la Caspasa-1 como gen sensibilizador a radio y quimioterapia es independiente de las vías de JNK y p38
}

G. Vassaux¹, P. Mancheño-Corvo² ${ }^{2}$ M. López-Barahona², M. Quintanilla ${ }^{3}$, R. Francisco-Álvarez², J. Hernández-Losa ${ }^{4}$, R. Lopes ${ }^{1}$, P. Martín-Duque ${ }^{1,2}$

\section{Resumen}

El efecto citotóxico de las drogas antitumorales es producido mediante la inducción de apoptosis. Esta observación implica la posibilidad de que los factores que afecten la activación de caspasas pueden ser determinantes importantes como sensibilizantes a los tratamientos antitumorales. Aquí, examinamos el efecto de la sobreexpresión de caspasa-1 en la respuesta a la quimio y radioterapia. La expresión de la caspasa-1 mediada por un vector adenoviral fue capaz de matar directamente a las células y de sensibilizar las restantes a cisplatino o radiación gamma in vitro. En células HeLa transfectadas establemente con caspasa-1, la sensibilización a cisplatino fue debida a una amplificación en la vía mitocondrial de apoptosis inducida por cisplatino pero este efecto es independiente del estado de p53, JNK o p38 en la célula.

\section{Palabras clave:}

Caspasa-1. Radio y quimiosensibilización. Quinasas y p53.

Oncología, 2005; 28 (8):394-406

\footnotetext{
${ }^{1}$ Cancer Research-UK. Molecular Oncology Unit. Barts and The London School of Medicine and Dentistry, John Vane Science Centre, Charterhouse Square. London (United Kingdom)

${ }^{2}$ Universidad Francisco de Vitoria. Facultad de Ciencias Biosanitarias. Pozuelo de Alarcón. Madrid (España)

${ }^{3}$ Instituto de Investigaciones Biomédicas CSIC. Madrid (España)

${ }^{4}$ Dpto. de Anatomía Patológica. Hospital Vall d'Hebron. Barcelona (España)
} 


\section{Summary}

The cytotoxic effect of anticancer drugs has been shown to involve induction of apoptosis. This observation raises the possibility that factors affecting caspase activation might be important determinants as anticancer drug sensitivity. Ectopic expression of caspase-1 has been shown to trigger apoptosis. Here, we examine the effect of caspase-1 over-expression on the response to chemotherapy and radiotherapy. Caspase-1 expression mediated by an adenoviral vector was able to kill directly cells and to sensitize the remaining cells to cisplatin or $\gamma$-radiation in vitro. In HeLa cells stably transfected with caspase-1, sensitisation to cisplatin was due to an amplification of the cisplatin-induced mitochondrial apoptotic pathway activation but this effect is independent of p53, JNK or p38 status.

Key words: Caspase-1. Chemo and radiosensitization. Kinases and p53.

\section{Introducción}

El cáncer es la primera causa de mortalidad, en los países occidentales, entre los sujetos de 40 a 60 años, y la segunda si nos centramos en la población mayor de 60 años, sólo situada por detrás de las enfermedades cardiovasculares. Los tratamientos, centrados únicamente en la eliminación del tumor primario (generalmente mediante la cirugía), tan sólo son efectivos en una tercera parte de los enfermos intervenidos, siendo los niveles de curación equiparables a los existentes hace 15 años, en el caso de los tumores sólidos epiteliales. Debido a esta incapacidad de solventar el problema mediante los abordajes clásicos, los objetivos actuales en el tratamiento de esta enfermedad incluyen el desarrollo de otras estrategias alternativas, como la búsqueda de mecanismos antiangiogénicos, la inmunoterapia o la terapia génica.

La resistencia a drogas quimioterápicas constituye un problema clínico grave y, en muchos casos, es la causa del fracaso en los tratamientos de los tumores. Las líneas celulares que sufren resistencia múltiple a fármacos (MDR), no sólo la presentan a los fármacos para los que han estado expuestas, sino hacia un espectro más amplio de compuestos que aparentemente no están relacionados. Por esto, otra de las estrategias más interesantes a considerar sería la combinación de la terapia génica con los métodos clásicos de tratamiento de cáncer, como serían los agentes quimioterápicos o la radioterapia ${ }^{1,2}$. Esta última, es el tratamiento de elección para la mayoría de los tumores sólidos, pero la tolerancia de los tejidos normales que rodean la zona a tratar condiciona las dosis que se pueden administrar al tumor. Estas dosis se podrían modificar mediante una aproximación que combinara la radioterapia convencional con la introducción de genes que aumentaran la eficacia en la dosis administrada, consiguiendo un mejor efecto a menor dosis.

El mayor desafío en el tratamiento del cáncer es tratar células que se han convertido en resistentes a los tratamientos por radio o quimioterapia disponibles. Hasta ahora se han identificado algunos genes que sensibilizan a la radio y quimioterapia, como TNF- $\alpha$ y el gen adenoviral E1a o recientemente la caspasa-1 o ICE (Martín-Duque y col, manuscrito en publicación). La expresión de estos genes bajo el control de promotores antitumorales u otros, como el promotor inducible por radiación Egr-1, que se ha combinado con la citoquina radiosensibilizante TNF- $\alpha$ y que se encuentra en ensayos clínicos en fase $\mathrm{I}^{3}$, ayudarían a controlar y reducir los daños producidos por la radiación ${ }^{4}$ o quimioterapia ${ }^{5,6}$, incrementando aún más el atractivo de esta estrategia.

Entre los mecanismos de resistencia a drogas se encuentra el fallo en la apoptosis. Por esto, la activación directa de las caspasas podría ser una estrategia efectiva para matar las células que son resistentes. En terapias experimentales de cáncer, la expresión de Caspasa-1 ha demostrado tener cierta actividad antitumoral por sí misma, o combinada en un protocolo de inmunoterapia ${ }^{7}$. Además, en estudios clínicos se ha sugerido que ICE podría estar asociada 
con la regresión espontánea en ciertos neuroblastomas en pacientes ${ }^{8}$ y a que la alta expresión de esta proteína se relaciona con una buena respuesta a quimioterapia en leucemias y linfomas ${ }^{9}$. Estas observaciones nos llevaron a estudiar recientemente el efecto de la sobreexpresión de ICE en respuesta a la radio y quimioterapia en un modelo experimental in vitro e in vivo, llegando a concluir que al igual que E1a de adenovirus, caspasa- 1 es un gen radio y quimiosensibilizante in vitro e in vivo por mecanismos independientes de $\mathrm{p} 53^{10}$.

Pero aunque se sabe que estos genes son sensibilizadores a los tratamientos, aún no se conoce el mecanismo de acción. Estudios previos han correlacionado la inducción de apoptosis y de la inducción de quimio y radiosensibilidad con la unión al grupo de la proteína del retinoblastoma y al de la proteína p300 ${ }^{11}$, si bien en los casos de TNF- $\alpha$ o caspasa- 1 el mismo efecto asociado a estas proteínas no sería explicable $^{12,13}$.

Por otra parte, para el caso de la proteína adenoviral E1a, que sensibiliza las células a los efectos citotóxicos tanto de la radiación ionizante como a una gran variedad de drogas antitumorales, como 5Fluorouracilo, etopósido, adriamicina, cisplatino o doxorrubicina se ha comprobado que este efecto es independiente del estado de p53 existente en la célula y del resto de alteraciones oncogénicas pero dependiente de una serie de quinasas ${ }^{14-16}$.

Por todo esto, decidimos estudiar si la expresión exógena de la caspasa-1 era capaz de inducir sensibilidad a tratamientos radio y quimioterápicos y si en estos efectos estaban implicados los mecanismos descritos anteriormente, como eran las vías de p53, JNK, p38 o la familia de las IAPs.

\section{Materiales y métodos}

\section{Plásmidos}

El cDNA de la Caspasa-1 fue amplificado por PCR con el siguiente par de cebadores:

(Directo CGGGGTACCCCATGGCCGACAAGGTCCTG y reverso: CTAGTCTAGATGCCCACAGACATTC) usando el vector ICE-pBluescript como molde (amablemente cedido por el Dr. Fueyo). El producto de PCR fue clonado en el vector pEF6/V5-His-TOPO (Invitrogen, Pailsley, UK) y se- cuenciado. Fue elegido uno de los clones, que contenía el cDNA insertado en la orientación correcta. En los experimentos de transfección, se utilizó el vector vacío pEF6/V5-His-TOPO como control.

El cDNA de la caspasa-1 fue insertado entre los sitios Eco RV/Kpn I de pShuttle ${ }^{16}$ para generar pShICE. Una vez linearizado con Pme I, pSh-ICE fue recombinado con pAdeasy1, tal y como se había descrito previamente ${ }^{16}$, para generar pAd-ICE. Los recombinantes correctos, fueron seleccionados mediante digestiones con enzimas de restricción.

\section{Vectores adenovirales}

El adenovirus E1- que contiene el gen de la proteína de la fluorescencia verde (GFP), se obtuvo de Qbiogene (Cambridge, UK), y el Ad-Mock (vector de Ad-5 con la región E1 delecionada y que no contenía ningún transgén) fue amablemente cedido por el Dr. Mc Neish ${ }^{17}$.

El virus Ad-ICE fue generado tras la transfección de pAd-ICE en células 293. El virus fue expandido, purificado y titulado como se había descrito anteriormente ${ }^{18}$.

\section{Líneas celulares}

La línea de carcinoma cervical HeLa, las líneas celulares de páncreas Panc-O2, HPAF y Panc-1 y las líneas de tumores de próstata humanas DU-145, PC3, BHP-1, LNCaP fueron obtenidas de la colección del servicio de investigación celular de Cancer Research-UK. Las células fueron crecidas en Dulbecco Modified Eagle's medium (DMEM) o en RPMI 1640 que contenía suero bovino fetal al 10\% en presencia de antibióticos.

Se transfectaron $10^{5}$ células HeLa por pocillo con $0.4 \mathrm{mg}$ de DNA, en placas de 6 pocillos, usando Effectene transfection reagent (Qiagen, Crawley, UK), y siguiendo los protocolos de la casa comercial con mínimas modificaciones, para construir las líneas celulares HeLa-TOPO y HeLa-ICE. Los clones resistentes a Blasticidina S HCl (Invitrogen, Paisley, UK) fueron seleccionados a dosis de $10 \mu \mathrm{g} / \mathrm{ml}$.

\section{Ensayo enzimático de Caspasa-1}

Aunque la forma p45-proICE se encuentra en células HeLa normalmente, éstas no forman la protea- 
sa activa ${ }^{19}$. La actividad enzimática de Caspasa-1 se estudió usando el kit de ensayo "Caspase-1/ICE Colorimetric Protease Assay kit" (MBL, Medical \& Biological Laboratories Co, LTD, Japan). Siguiendo las instrucciones de la casa comercial, este método se basa en el corte del sustrato YVAD-pNA en presencia o ausencia del inhibidor selectivo de caspasa1, YVAD-FMK.

Se sembraron $10^{6}$ células HeLa Topo o Hela ICE en placas de $6 \mathrm{~cm}$ y se trataron con $3 \mu \mathrm{g} / \mathrm{ml}$ de cisplatino. 24 horas más tarde, se contaron las células y se obtuvo un precipitado celular de $5.10^{6}$ células que se lavaron dos veces con PBS frío. La actividad de la caspasa-1 fue medida de acuerdo al protocolo de la compañía. Las muestras fueron leídas a $400 \mathrm{~nm}$ en un espectrofotómetro usando una cubeta de cuarzo. Se define la actividad específica de la caspasa-1 como la diferencia en absorbancia unidad/hora/mg de proteína entre incubación de muestras en ausencia y en presencia del inhibidor de caspasa-1, YVAD-FMK.

\section{Detección de DNA genómico por PCR, en células HeLa-Topo y HeLa-ICE}

Se sembraron $10^{6}$ células HeLa-Topo o HeLa-ICE en placas de cultivo de $6 \mathrm{~cm}$ de diámetro y su DNA genómico fue extraído con el kit GenElute MAMMALIAN GENOMIC DNA KIT (Sigma Aldrich, USA) y la PCR fue realidada con el kit Opti-Prime PCR Optimization kit (Stratagene, UK) y el siguiente par de cebadores. Directo: CGGGGTACCCCATGGCCGACAAGGTCCTG; y Reverso: CTAGTCTAGATGCCCACAGACATTC

\section{Ensayo de citotoxicidad in vitro}

$2 \times 10^{4}$ células de cada línea celular fueron sembradas en placas de 24 pocillos con $1 \mathrm{ml}$ de DMEM al $10 \%$ de suero, con la única excepción de los experimentos de radiación, en los que se sembraron únicamente $10^{3}$ células. 24 horas más tarde, las células fueron infectadas con un rango de 1-10 PFU por célula dependiendo de la infectividad de cada línea celular obtenida anteriormente. Al día siguiente se administraron diversas concentraciones de cisplatino (Sigma-Aldrich, Poole, UK), paclitaxel (Taxol, Calbiochem, La Jolla, CA), o radiación gamma. Para los experimentos en HeLa-Topo o HeLa-ICE, el tra- tamiento comenzó 24 horas después de sembrar las células. Al cabo de 5 o 7 días de que comenzara el tratamiento se añadieron $100 \mu \mathrm{l}$ de MTT $(5 \mathrm{mg} / \mathrm{ml})$, (Sigma-Aldrich) y se incubaron las células durante 2 horas a $37^{\circ} \mathrm{C}$, para posteriormente disolver este colorante en DMSO y así poder medir la densidad óptica a $540 \mathrm{~nm}$.

\section{Western blots}

Se sembraron $10^{6}$ células HeLa-Topo o HeLa-ICE en placas de cultivo de $6 \mathrm{~cm}$ de diámetro. Al día siguiente, las células fueron tratadas con dosis de 5 a $40 \mathrm{mg} / \mathrm{ml}$ de cisplatino y recogidas tras 4 horas de tratamiento. Las células y los sobrenadantes se recogieron en un precipitado al que se añadió $100 \mu \mathrm{l}$ de buffer de lisis (25 mM HEPES $\mathrm{pH}=7.5 ; 0.3 \mathrm{M}$ $\mathrm{NaCl} ; 1.5 \mathrm{mM} \mathrm{Cl}{ }_{2} \mathrm{Mg}, 0.2 \mathrm{mM}$ EDTA, $0.5 \%$ ácido deoxicólico, $1 \%$ Triton X-100, 0.1\% SDS, $20 \mathrm{mM}$ B-glicerofosfato). El homogeneizado resultante fue después sonicado en hielo.

Para el caso de la expresion de GFP se sembraron $10^{6}$ células Panc-O2, HPAF, DU-145, PC-3, BHP-1 o LNCaP por pocillo en placas de 6 pocillos y se les permitió crecer 24 horas antes de ser infectadas con células 0.5 a 20 pfu/célula. A las 48 horas post-infección se recogieron las células en un precipitado y el sobrenadante y la proteína fue extraída de igual modo al descrito anteriormente.

Se separaron 20 microgramos de proteína en geles al 10-15\% de SDS-poliacrilamida y se pasaron a filtros de nitrocelulosa mediante transferencia semiseca. Los anticuerpos primarios utilizados fueron antip38 (1:300; Cell Signaling Technologies) anti-JNK (1:300; Sta. Cruz) y anti-GFP monoclonal de ratón, 3E1 (1:4000; Cancer Research-UK Monoclonal Antibody Services). El anticuerpo secundario en todos los casos, fue uno de conejo antiratón (1:1500). La unión de los anticuerpos fue visualizada usando ECL (Amersham Pharmacia Biotech, Little Chalfont, UK).

\section{PCR en tiempo real}

Se sembraron $10^{6}$ células HeLa-Topo o HeLa-ICE en placas de cultivo de $6 \mathrm{~cm}$ de diámetro. Al día siguiente, las células fueron tratadas con $0,0.3$ o 1 $\mu \mathrm{g} / \mathrm{ml}$ de cisplatino y recogidas tras 18 horas de tratamiento. El RNA fue extraído usando Trizol (Invi- 
trogen) siguiendo el protocolo de la compañía. El RNA total fue resuspendido en $100 \mu 1$ de agua libre de RNAsa. Para eliminar el DNA genómico residual se usaron los kit RNeasy (QIAGEN) y RNase-free DNAse kit (QIAGEN). El RNA (2 $\mu \mathrm{g})$ fue retrotranscrito usando el kit TaqMan reverse transcription reagents (ABI). Las muestras fueron analizadas por triplicado y las reacciones de PCR en tiempo real se realizaron usando SYBR green PCR Master Mix (ABI) en un detector de secuencias ABI PRISM 7700. Las curvas estandar para los genes diana y el control endógeno se usaron para la cuantificación. Los cebadores directo y reverso para cIAP1, cIAP-2, XIAP y PGK-1 (control endógeno) fueron diseñados usando el software Primer express software y usados a una concentración de $300 \mathrm{ng}$. Sus secuencias fueron: cIAP1:TGTTGTCAACTTC A G AT A C C A C T G G / C AT C AT G A C A G CATCTTCTGAAGA,cIAP2:GGACAGGAGTTCATCCGTCAAG/TGGATAATTGATGACTCTGCATTTTC, XIAP: GACAGTATGCAAGATGAGTCAAGTCA/GCAAAGCTTCTCCTCTTGCA, PGK-1: TGGAGAACCTCCGCTTTCAT/TGGCTCGGCTTTAACCTTGT.

\section{Resultados}

\section{Uso de un vector adenoviral para la expresión de Caspasa-1 en líneas celulares de diversos orígenes}

Anteriormente se había descrito que los tumores de próstata primarios mostraban una deficiencia en la expresión de la proteína de la caspasa- 1 comparados con tejido prostático normal ${ }^{20}$ pero, por el contrario en líneas tumorales de páncreas se veía el fenómeno opuesto al compararlas con tejido normal ${ }^{21}$. Nos planteamos realizar un estudio en un amplio panel de tumores entre los que incluíamos varios tumores de tipo pancreático o prostático.

Entre éstas estudiamos una serie de líneas celulares de próstata (DU-145, PC3, BHP-1 o LNCaP), páncreas (Panc-O2, Panc-1, HPAF) o cervicales (HeLa). Antes de infectarlas con un adenovirus que exprese la caspasa-1, buscamos la multiplicidad de infección (m.o.i) con la que trabajaríamos posteriormente mediante la infección de las mismas con un adenovirus Ad-GFP. Para cada línea celular elegi- mos la cantidad de virus que nos garantice un 100\% de transducción del gen sin una toxicidad viral inespecífica (datos no mostrados). Infectamos las células a m.o.i de 0.5 a 20 pfu/célula de Ad-GFP. En la Figura 1 mostramos los niveles de expresión de GFP en cada línea celular tras 48 horas de la infección con Ad-GFP. En todas las líneas los niveles de expresión a las 48 horas y a las dosis elegidas, fueron similares por microscopía de fluorescencia (no mostrado) o por western-blot.

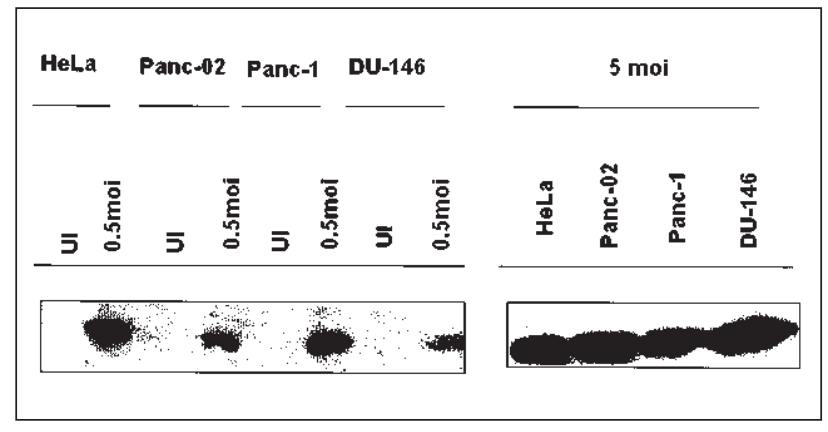

Figura 1. Niveles de expresión de proteína GFP en cada línea celular tras 48 horas de la infección con Ad-GFP. Se sembraron $10^{6}$ células Panc-O2, HPAF, DU-145, PC-3, BHP-1 o LNCaP por pocillo en placas de 6 pocillos y se les permitió crecer 24 horas antes de ser infectadas con células 0.5 a 20 pfu/célula. A las 48 horas post-infección, se recogieron las células en un precipitado y el sobrenadante y la proteína fue extraída para realizar un western-blot con un anticuerpo antiGFP.

Como se observa en la Figura 2a, únicamente con la infección con Ad-ICE se produce una marcada disminución en la supervivencia celular, que en algunos casos llega hasta al 80\% como en la línea LN$\mathrm{CaP}$. Este efecto es muy marcado al compararlo tanto con las células sin infectar como con el adenovirus vacío, si bien este adenovirus vacío respecto a las células sin infectar no produjo prácticamente ningún efecto, por lo que podemos pensar que esta muerte celular sería producida por el transgen (ICE).

\section{Sensibilización in vitro por parte de un Ad-ICE a los tratamientos antitumorales}

Para probar la sensibilización a los tratamientos convencionales producida por la sobreexpresión de ICE mediante la infección adenoviral, incubamos diversas líneas celulares con un Ad-ICE y tras la infección administramos diversas dosis de cisplatino o radiación gamma durante 5 o 7 días. 


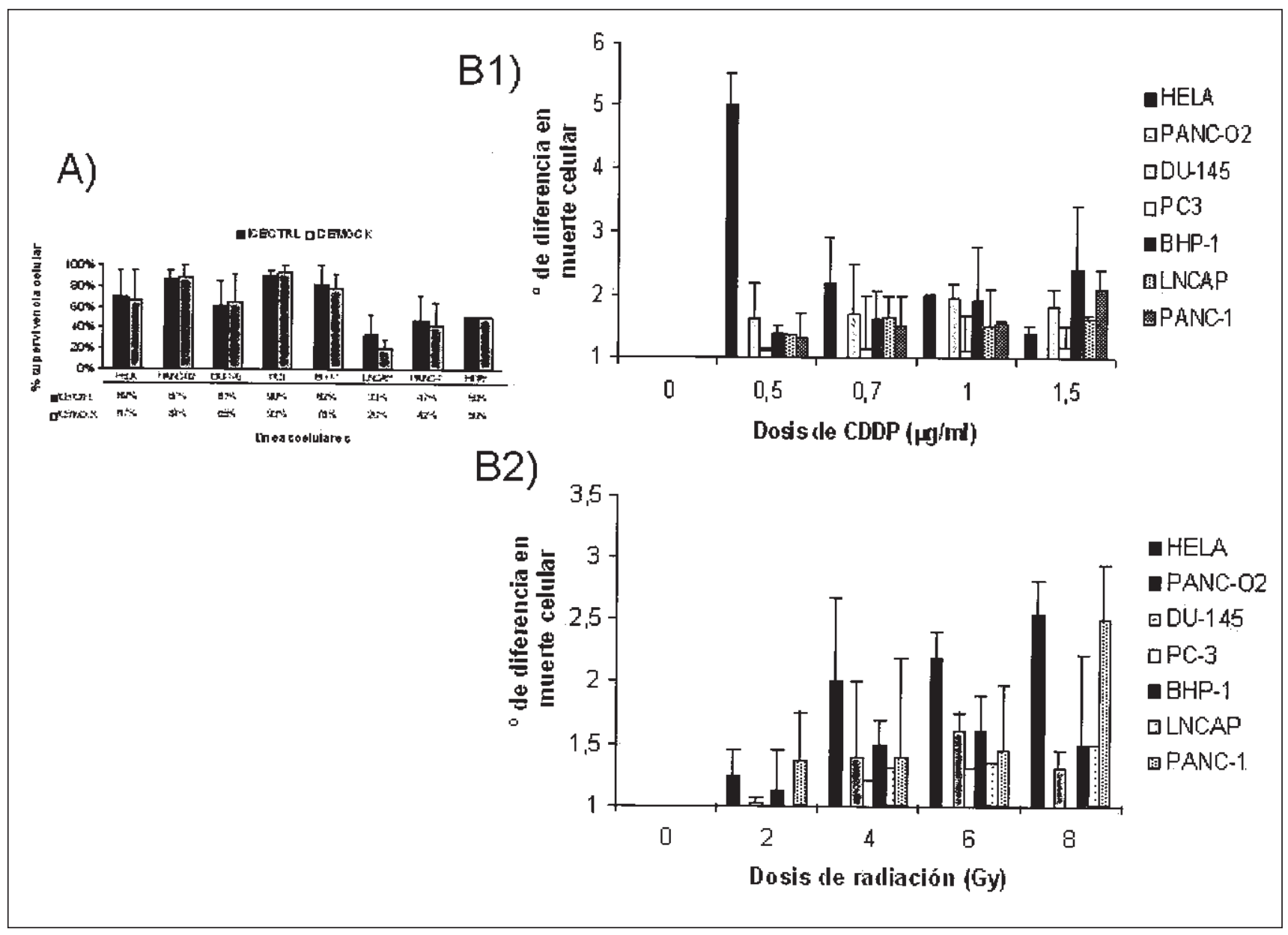

Figura 2. A) Efecto de la infección de Ad-ICE en supervivencia celular. Se sembraron 2x10 4 células, en placas de 24 pocillos y se les dejó crecer 24 horas antes de ser infectados con un Ad-ICE o Ad-Mock a dosis de 1-10 unidades formadoras de placa (p.f.u.) por célulal. Para cada línea celular, la dosis de virus usado fue la necesaria para infectar el 100\% de las células.La viabilidad celular fue medida 5 días post-infección por ensayo de MTT. El \% de células supervivientes, es el porcentaje de células vivas infectadas por AdICE respecto al número de células vivas tras la infección con Ad-Mock. Cada experimento fue realizado por triplicado B) Efecto de la infección con Ad-ICE en la radio o quimiosensibilización in vitro: Se sembraron $2 \times 10^{4}$ células $\left(10^{3}\right.$ células por pocillo en los experimentos de radiación) en placas de 24 pocillos y permitidos crecer durante 24 horas antes de ser infectados con Ad-ICE o Ad-Mock en un rango de dosis de 1-10 unidades formadoras de placa (p.f.u.) por célula. Para cada línea celular, la dosis de virus usada fue suficiente para infectar el $100 \%$ de las células. El día posterior a la infección, las células fueron tratadas con cisplatino (B1) o radioterapia (B2) y 5 (para CDDP) o siete (para radioterapia) días tras el tratamiento, la viabilidad celular fue mediada por MTT. Los experimentos fueron realizados por triplicado para cada línea celular y tratamiento. Los datos presentados son la media \pm SD de 3 experimentos realizados por triplicado.

Las Figuras $2 b$ y 3 muestran que este efecto sensibilizante es altamente dependiente de la línea celular en estudio, aunque en general en todos los casos se pudo observar una marcada sensibilización a los tratamientos refiriéndolos a su Ad-Mock control. El rango de diferencia de muerte celular de las diversas líneas celulares infectadas con Ad-ICE/Ad-Mock fueron tan variables como de ser 5 veces superior para HeLa o dosis bajas de CDDP (Fig. 2.b1) a 2.5 para Panc-1 en radiación gamma (Fig. 2.b2), hasta no mostrar prácticamente ningún efecto en los casos de PC-3 o Panc-O2, células que a su vez eran también las más resistentes al virus por si mismo (Fig. 2a) y sin poderse concluir de este modo que sea la estirpe celular (páncreas o próstata) la clave de la sensibilización. 


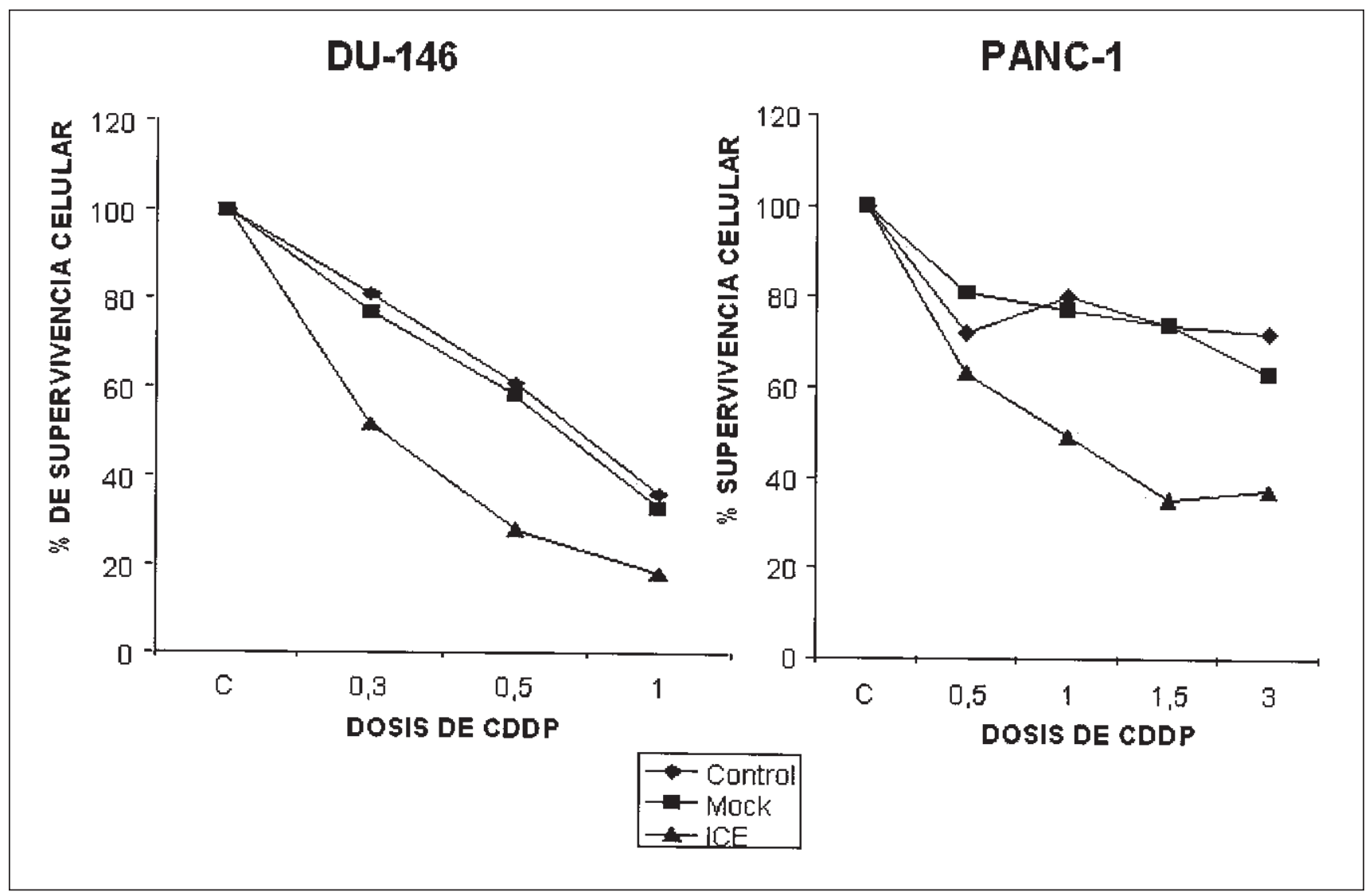

Figura 3. Efecto de la infección de Ad-ICE en viabilidad celular. Se sembraron 2x104 células, en placas de 24 pocillos y se les dejó crecer 24 horas antes de ser infectados con un Ad-ICE o Ad-Mock a dosis de 1-10 unidades formadoras de placa (p.f.u.) por célulal. Para cada línea celular, la dosis de virus usado fue la necesaria para infectar el $100 \%$ de las células. La viabilidad celular fue medida 5 días post-infección por ensayo de MTT. Cada experimento fue realizado por triplicado.

\section{Generación de una línea celular que sobreexprese caspasa-1}

Como hemos indicado anteriormente, el efecto del vector adenoviral que expresa caspasa-1 es capaz de inducir una marcada muerte celular en las distintas líneas celulares, que en algunos casos llega a ser muy marcado y que deja una pequeña población superviviente para continuar con los estudios de sensibilidad a los diversos tratamientos. Como se observa en la Figura 2b1, la línea celular HeLa mostraba, a dosis bajas de CDDP, una diferencia de 5 veces con respecto a su control infectado con AdMock. Por este motivo y porque en estas células existe la forma p45-proICE pero no son capaces de formar la proteasa activa, decidimos establecer una línea celular Hela que sobreexpresara caspasa-1 para examinar más profundamente la sensibilidad a la radio y quimioterapia in vitro.
La presencia del cDNA de la caspasa-1 en el genoma de las células HeLa-ICE fue detectado por PCR de DNA genómico, mientras que estaba ausente en la línea control HeLa-Topo (Fig. 4a). Para valorar si la caspasa-1 que habíamos detectado era funcional, realizamos un ensayo de medida de la actividad enzimática de ambas líneas celulares generadas. Se trataron ambas líneas con $0.3 \mu \mathrm{g} / \mathrm{ml}$ de cisplatino (CDDP), las actividades enzimáticas específicas fueron de 0.06 unidades de absorbancia/mg de proteína para HeLa-Topo tratada con cisplatino y 0.21 unidades de absorbancia/mg de proteína para HeLa-ICE tratada con cisplatino (Fig. 4b).

Para comparar el potencial de crecimiento, ambas líneas celulares fueron sembradas a día $0\left(2.10^{4}\right)$ en placas de 24 pocillos y el número de células fue contado a días 1, 5, 8, 13 y 15. La Figura 6b muestra como las células HeLa-ICE crecen significantemente más despacio que las control HeLa-Topo, in vitro, 


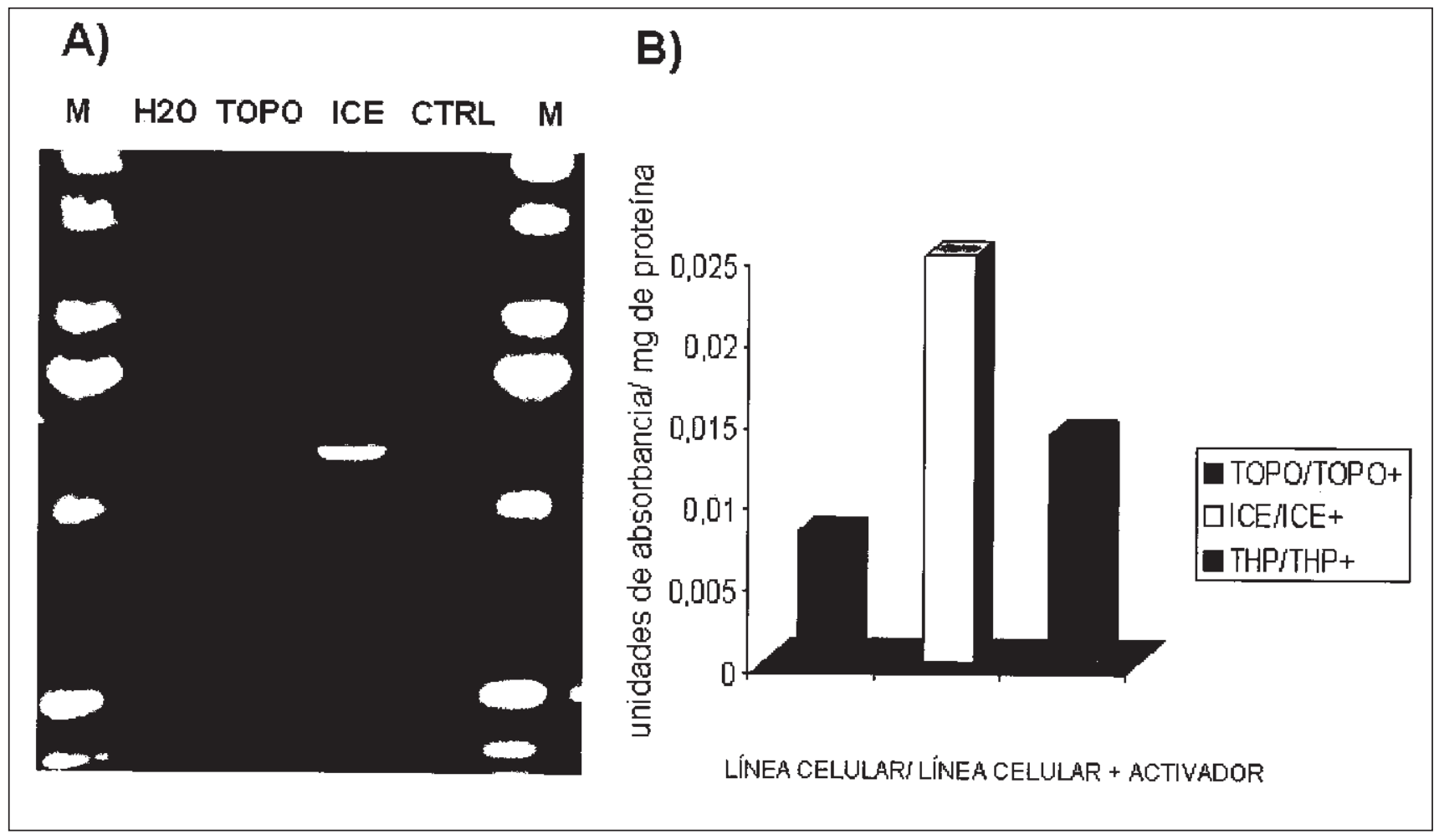

Fig 4) Detección de DNA genómico por PCR, en células HeLa-Topo y HeLa-ICE. A) Se sembraron $10^{6}$ células HeLa-Topo o HeLaICE en placas de cultivo de $6 \mathrm{~cm}$ de diámetro y su DNA genómico fue extraído con el kit GenElute MAMMALIAN GENOMIC DNA KIT (Sigma Aldrich, USA) y la PCR fue realidada con el kit Opti-Prime PCR Optimization kit (Stratagene, UK) y el siguiente par de cebadores. Directo: CGGGGTACCCCATGGCCGACAAGGTCCTG; y Reverso: CTAGTCTAGATGCCCACAGACATTC B) Actividad enzimática de la caspasa-1. Se define la actividad específica de la caspasa-1 como la diferencia en absorbancia uni$\mathrm{dad} / \mathrm{hora} / \mathrm{mg}$ de proteína entre incubación de muestras en ausencia y en presencia del inhibidor de caspasa-1, YVAD-FMK.

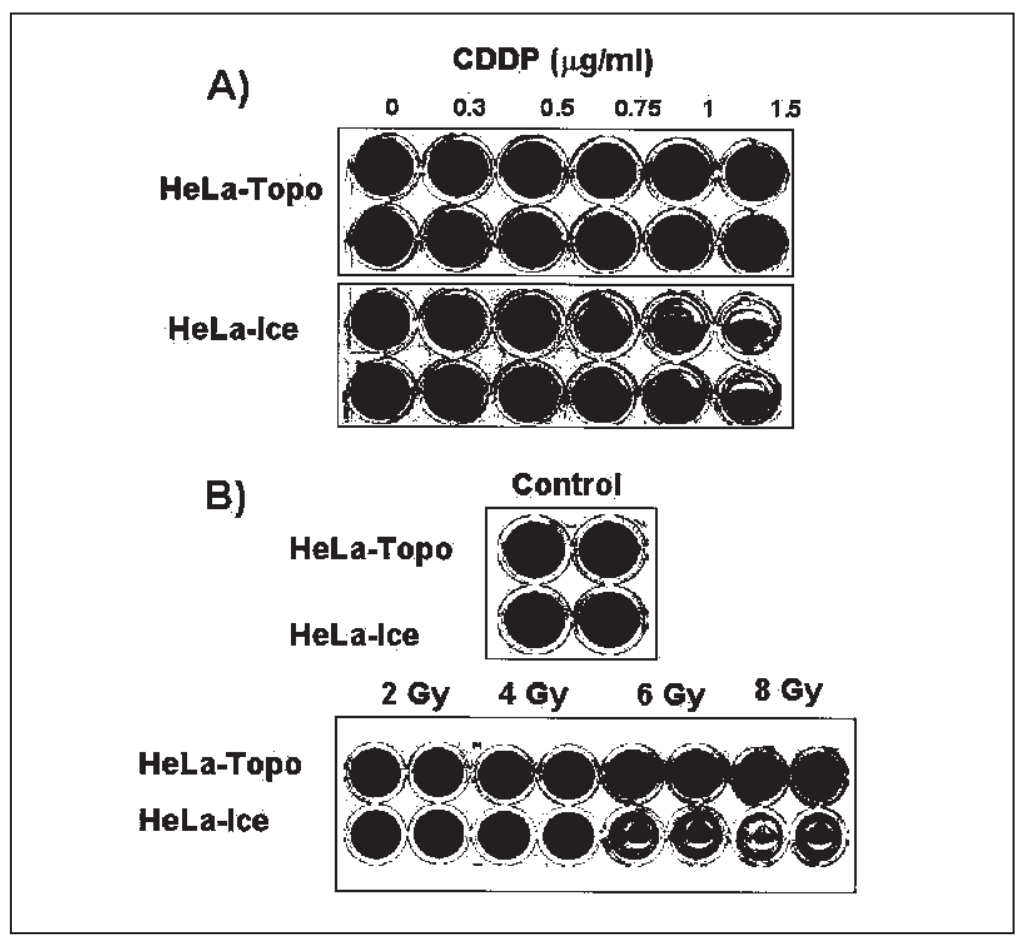

Figura 5. A) Efecto del cisplatino en células HeLa Topo o HeLa-ICE. Se trataron $2.10^{4}$ células HeLa-Topo o HeLa-ICE con diversas concentraciones de cisplatino. Cinco días tras el tratamiento, el número de células viables fue determinado usando un ensayo MTT. B) Efecto de la radiación gamma en células HeLa-Topo o HeLa-ICE. Se sembraron $10^{3}$ células HeLa-Topo o HeLa-ICE en una placa de 24 pocillos. Al cabo de 24 horas, las células fueron sometidas a diferentes dosis de radiación gamma y al cabo de siete días el número de células en el pocillo fue determinado mediante un ensayo MTT. 


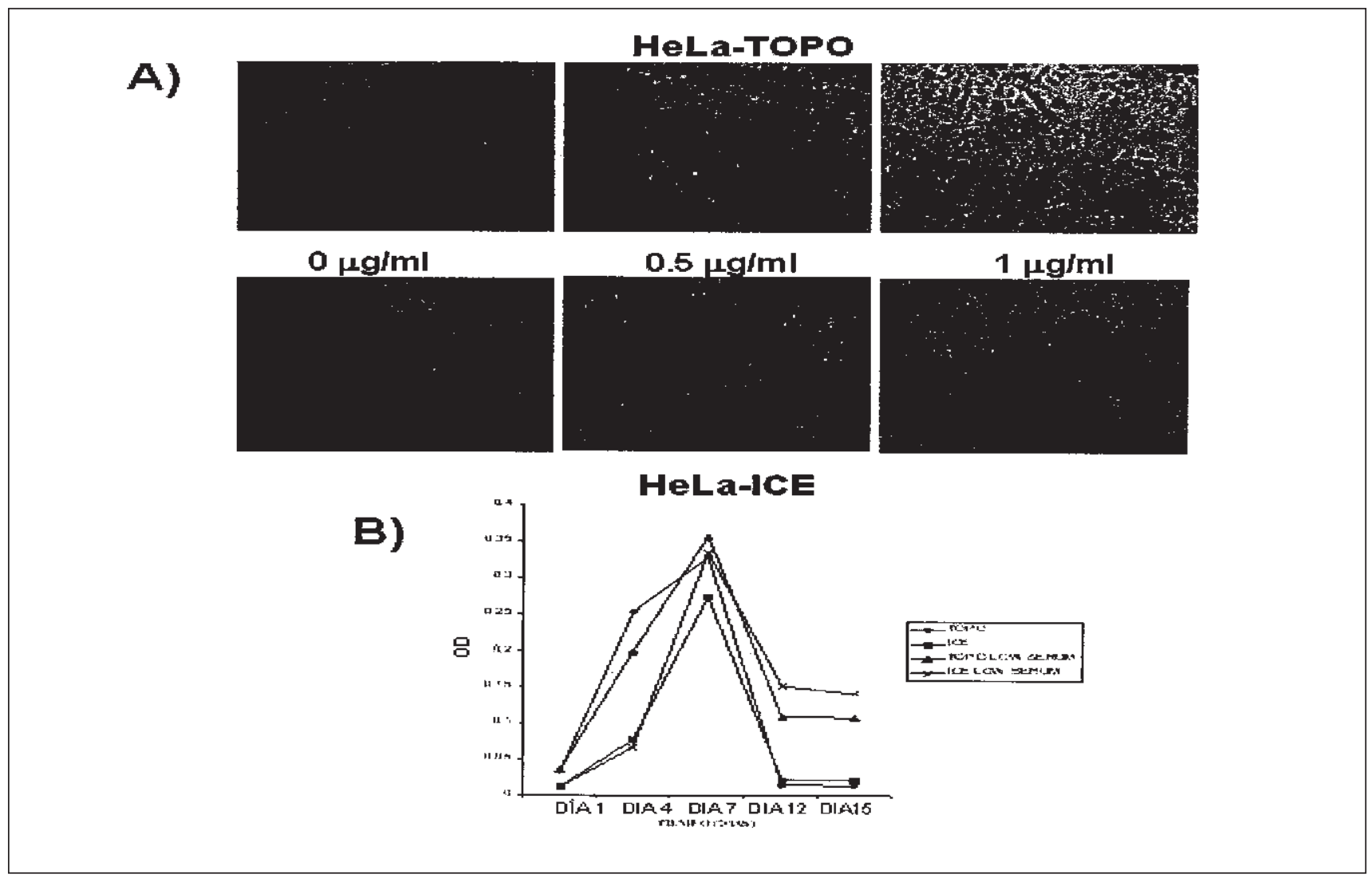

Figura 6. A) Efecto de la sobreexpresión de la caspasa-1 en la inducción de apoptosis en células HeLa. Se trataron 2.104 células HeLaTopo o HeLa-ICE con diversas concentraciones de cisplatino. 48 horas tras el tratamiento, las células fueron fotografiadas observándose una numerosa población de células en suspensión en el caso de HeLa-ICE que no se encontraban de la misma manera en el caso de HeLa-TOPO .B) Efecto de la sobreexpresión de la caspasa-1 en el potencial de crecimiento de la células HeLa. Ambas líneas celulares fueron sembradas a día $0\left(2.10^{4}\right)$ en placas de 24 pocillos con suero al $10 \%$ o al $2 \%$ y el número de células fue contado a días 1, 5, 8, 13 y 15: Las células alcanzaron confluencia a día 10. Estos datos presentan la media \pm SD de 3 experimentos.

al igual que se observa también en el crecimiento tumoral en los ratones (Martín-Duque y col, 2005. En publicación).

\section{La sobreexpresión de caspasa-1 sensibiliza a radio y quimioterapia in vitro}

El efecto de la sobreexpresión de caspasa-1 en la muerte celular inducida por distintos tratamientos fue estudiada al ser incubadas las células HeLa-ICE o HeLa-Topo con diversas concentraciones de drogas durante 5-7 días. En la Figura 5 añadimos un colorante vital a las células (MTT) al cabo de los días, que sólo teñirá a las células vivas. Se puede observar como la radiación gamma puede matar las células HeLa-Topo de manera dependiente de la dosis, mientras que en células HeLa este efecto está muy aumentado desde las primeras dosis de radiación (2 Gy). Con cisplatino podemos ver como este efecto es también muy marcado pero se encuentra más relacionado con las dosis añadidas.

\section{Vías de activación de la caspasa-1 para la inducción de apoptosis}

En un estudio paralelo pudimos observar como la marcada muerte celular existente en la línea celular HeLa-ICE, ante el tratamiento con drogas antitumorales (Fig. 6a), podía estar debida a una activación en la vía apoptótica mitocondrial (Resultados no mostrados. Martín-Duque y col, 2005). En este trabajo se indicaba que la sobreexpresión de la caspasa-1 amplifica la vía apoptótica mitocondrial inducida por CDDP, sin afectar la vía apoptótica inducida por ligando. 


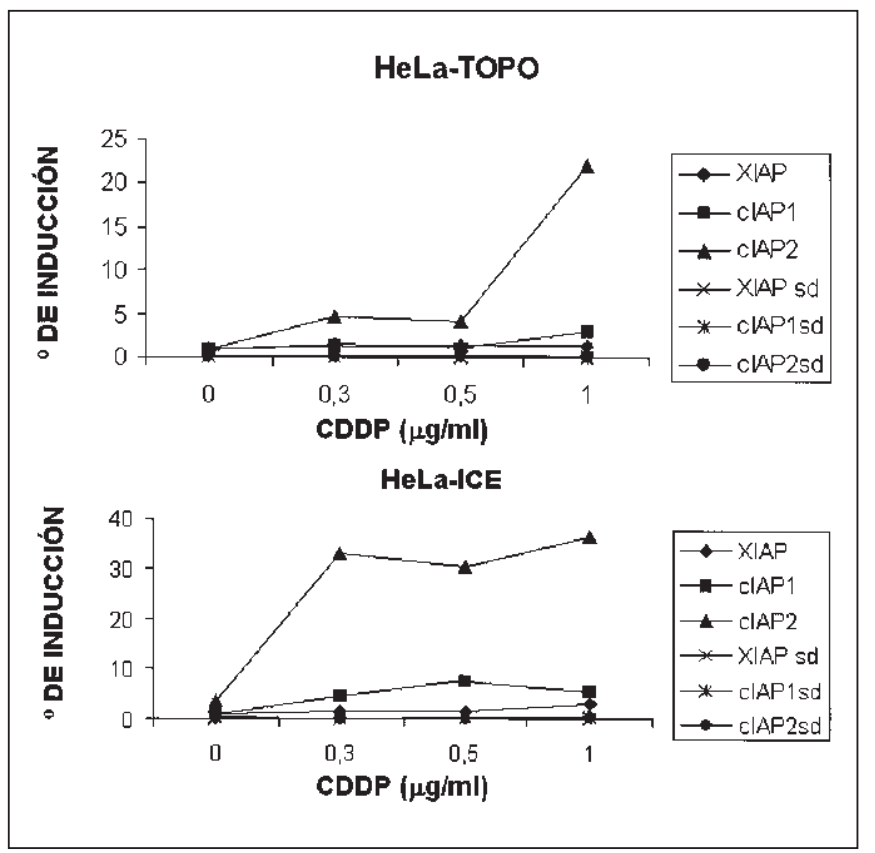

Figura 7. Análisis de PCR en tiempo real de inhibidores de apoptosis en líneas celulares HeLa-Topo y HeLa-ICE. Se sembraron $10^{6}$ células HeLa-Topo o HeLa-ICE en placas de culltivo de $6 \mathrm{~cm}$ de diámetro. Al día siguiente, las células fueron tratadas con $0,0.3,0.5$ o $1 \mathrm{mg} / \mathrm{ml}$ de cisplatino y recogidas tras 18 horas de tratamiento. Se retrotranscribió $2 \mu \mathrm{g}$ de RNA para realizar la PCR en tiempo real para cIAP-1, cIAP2, XIAP y PGK-1 (control endógeno, no mostrado). Muestras de 3 experimentos por separado fueron analizados por triplicado.

Pero curiosamente este efecto en la cascada apoptótica fue acompañado por un aumento en los niveles de los transcritos de los inhibidores de apoptosis del tipo de XIAP, cIAP1 y 2 (Fig. 7). En particular existe un marcado incremento en la expresión de cIAP2 en ambas líneas celulares a dosis de $1 \mathrm{mg} / \mathrm{ml}$, mientras que este incremento se podría observar en HeLa-ICE desde el inicio del tratamiento.

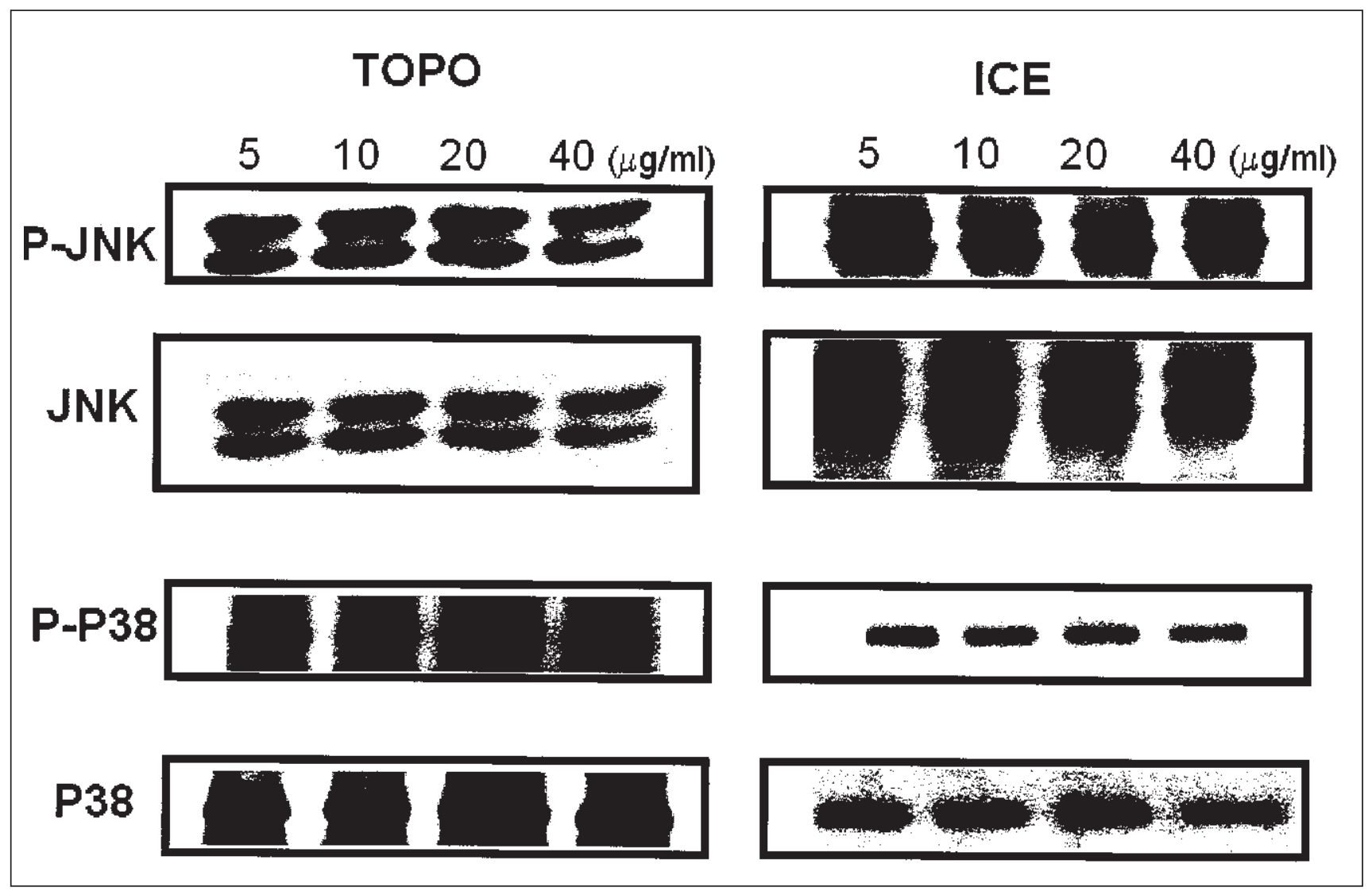

Figura 8. Análisis de la inducción de quinasas en la líneas celulares HeLa-Topo y HeLa-ICE, ante tratamientos antitumorales. Se sembraron $10^{6}$ células HeLa-Topo o HeLa-ICE en placas de cultivo de $6 \mathrm{~cm}$ de diámetro. Al día siguiente, las células fueron tratadas con dosis de 5 a $40 \mathrm{mg} / \mathrm{ml}$ de cisplatino y recogidas tras 4 horas de tratamiento en buffer de lisis. Se separaron 20 microgramos de proteína en geles al 10-15\% de SDS-poliacrilamida y se pasaron a filtros de nitrocelulosa mediante transferencia semiseca. Los anticuerpos primarios utilizados fueron anti-p38 (1:300; Cell Signaling Technologies) y anti-JNK (1:300; Sta. Cruz). 


\section{G. Vassaux y cols.}

Además, a causa de la fuerte activación de JNK y p38 MAPK observado en células tratadas con varias señales implicadas en stress (entre las cuales se encuentran CDDP y radiación gamma) y que llevan a apoptosis, el papel de estas quinasas en la respuesta a estos tratamientos está siendo profundamente estudiado. Por ello decidimos estudiar si existía una activación de estas quinasas en nuestro modelo de sensibilidad a los tratamientos, al igual que había ocurrido en otros genes sensibilizadores como el caso de E1 ${ }^{16}$. Desafortunadamente, en nuestro caso no pudimos observar activación ni de JNK ni de p38 en el caso de HeLa-ICE respecto a su control (Fig. 8).

\section{Discusión}

En este estudio, describimos que la sobreexpresión de la caspasa-1 por un adenovirus es capaz de matar un porcentaje de células infectadas. Además, mostramos que la porción de células supervivientes que expresaban caspasa-1 muestran una elevada sensibilidad a la radio y quimioterapia. En el caso de sensibilización al cisplatino, el efecto de la caspasa1 es acompañado por un aumento en los niveles de mRNA de moléculas antiapoptóticas tales como XIAP, cIAP1 y cIAP2, pero sin observarse cambios en quinasas como JNK o p38.

Estos datos están en concordancia a algunos resultados clínicos que asocian la expresión de la caspasa- 1 con una respuesta favorable a la quimioterapia. En leucemia mieloide aguda, la expresión elevada de caspasa-1 era indicativa de una buena respuesta clínica a la quimioterapia ${ }^{9} \mathrm{o}$ un pronóstico favorable. Altos niveles de caspasa-1 han sido correlacionados con regresión espontánea en neuroblasto$\mathrm{ma}^{23,24}$. También, concentraciones séricas de caspasa-1 en pacientes con osteosarcoma de alto grado mostraban una buena correlación a la quimioterapia $^{25}$. En este estudio, los niveles séricos de caspasa1 eran mayores en pacientes con buenos grados de regresión que en aquellos pacientes que era malo ${ }^{25}$. Del mismo modo, los altos niveles de expresión de caspasa-1 observados en los tumores astrogliales de bajo grado fueron observados en áreas apoptóticas de tumores con mayor supervivencia ${ }^{26}$. Un estudio inmunohistoquímico reveló que la mayoría de los tumores de próstata primarios no expresan caspasa-1 comparado con tejido prostático normal ${ }^{21}$. Este grupo de datos sugieren que la expresión de caspasa-1 está posiblemente regulada negativamente durante la formación de los tumores primarios de próstata.

Por el contrario, se ha asociado un aumento de la expresión de caspasa-1 con peor pronóstico en otros tipos de malignidades. En cáncer de páncreas la sobreexpresión de caspasa-1 ha sido observada en la mayoría de las células a diferencia del tejido pancreático normal ${ }^{22}$, sugiriendo una función adicional de la caspasa- 1 .

Se han sugerido varias proteínas como radio y/o quimiosensibilizadores en el tratamiento del cáncer, de hecho, varias de ellas están siendo utilizadas en ensayos clínicos. De ellas, el transporte de p53 mediante adenovirus, es el caso mejor documentado ${ }^{27}$. Además, múltiples evidencias sugieren que la alteración de la funcionalidad de p53 reduce la respuesta a los agentes antitumorales ${ }^{28}$. Así, el reemplazamiento usando p53, en combinación con agentes que dañan el DNA es una estrategia usada en numerosos tumores $^{27}$. La proteína E1A de adenovirus tipo $5 \mathrm{y}$ alguno de los mutantes derivados de ella demostraron ser capaces de sensibilizar las células de carcinoma a la radio y quimioterapia de manera independiente de $\mathrm{p} 53$ in vitro ${ }^{29} \mathrm{e}$ in vivo en modelos muri$\operatorname{nos}^{30}$ y humanos ${ }^{31}$.

Estudios previos en algunas de las líneas celulares que estudiamos en el presente trabajo, han sido empleadas para correlacionar la sensibilidad o resistencia de las diversas líneas a los tratamientos antitumorales con factores genéticos descritos en la literatura $^{32,33}$. Algunas de estas vías genéticas involucran genes tan distintos como los de la familia de las IAP (cIAP1 y 2., XIAP), mutaciones en p53, miembros pro y antiapoptóticos de la familia de Bcl-2 (Bax., Bcl-2 o Bcl-xl), la dependencia a andrógeno o no, el estado intrínseco de caspasa-1. Ni el tipo de tumor o alguno de los factores estudiados, incluyendo la expresión de la caspasa-1 fue correlacionado con la respuesta mostrada por las líneas celulares a los diversos tratamientos.

El efecto en la cascada apoptótica fue acompañado por un aumento en los niveles de los transcritos de los inhibidores de apoptosis del tipo de XIAP, cIAP1 y 2. En particular, existe un fuerte incremento en la expresión de cIAP2 en ambas líneas celulares a dosis de $1 \mathrm{mg} / \mathrm{ml}$, mientras que este aumento en la señal ya se podría observar en HeLa-ICE des- 
de el principio del tratamiento. Esta marcada expresión de cIAP2 ante daño existente a la línea celular HeLa-ICE, podría ser debida a que la respuesta de la célula ante un fenómeno de apoptosis más temprano respecto a su control debe ser también anterior y de mayor intensidad.

Además, y al igual que en el caso del gen adenoviral E1a, este efecto sensibilizador parece ser independiente de p53, ya que en el caso de la línea celular HeLa, en la cual existe un efecto sensibilizador muy marcado, p53 se encuentra inactivada por E6 de HPV.

Otras de las vías que han sido implicadas en la apoptosis inducida por cisplatino o radiación gamma sería la activación de ciertas quinasas, como jun quinasa (JNK) o p38. Pero como se ha descrito previamente $^{34}$ el gen supresor de tumores p53, que es esencial para la apoptosis inducida por radiación, es un sustrato de JNK in vivo, y por lo tanto en ausencia de p53, no se produce activación de JNK. Además, también se ha descrito ${ }^{34}$ que la inducción de JNK es independiente de Caspasa-1. Estos resultados están de acuerdo con los datos descritos en este artículo en los que no se puede ver diferencias en JNK pese al efecto sensibilizador producido por Caspasa-1 y sugieren que la activación de JNK está o por encima de la cascada o independiente de la activación de proteasas tipo ICE. De igual manera, tampoco se pudo ver activación de p38, pero como se ha publicado con anterioridad, la radiación gamma no induce siempre JNK o p38 en todas las líneas celulares ${ }^{34}$.

La caspasa-1 ya ha demostrado algún efecto en terapia experimental de cáncer. El transporte de caspasa-1 por retrovirus ${ }^{35} \mathrm{y}$ adenovirus ${ }^{7}$ indujo apoptosis que se pudo relacionar in vivo con un efecto antitumoral. Comparando estos resultados con nuestras observaciones, se demuestra el potencial de la caspasa-1 para protocolos de terapia génica en donde el transporte de caspasa-1 podría ser usado en combinación con quimio o radioterapia.

En conclusión, proponemos el uso de la caspasa-1 como radio y quimiosensibilizador en protocolos de terapia génica, posiblemente combinando los vectores con promotores selectivos tumorales o de tejido para evitar efectos indeseables en otros tejidos. En este contexto, un buen candidato sería el cáncer de próstata primario, ya que además de que existen promotores específicos para este tumor, la expresión de caspasa-1 es prácticamente inexistente ${ }^{21}$.

\section{Agradecimientos}

Los autores quisieran agradecer al Dr. Carlos Parada, María Díaz, Lara González y Elvira Herrero su ayuda en el trabajo. Las investigaciones en los laboratorios de los autores son financiadas por Cancer Research-UK, el Programa Ramón y Cajal del Ministerio de Educación y Ciencia de España y la Universidad Francisco de Vitoria.

\author{
Correspondencia: \\ Dra. Ma P. Martín Duque \\ Facultad de Ciencias Biosanitarias \\ Universidad Francisco de Vitoria \\ Ctra. Pozuelo-Majadahonda, Km. 1,800 \\ E-28223 Pozuelo de Alarcón (Madrid) \\ e-mail: p.martin@ufv.es
}

\section{Bibliografía}

1. Heise C, Sampson-Johannes A, Williams A, Mc Cormick F, Von Hoff D, Kirn DH. ONYX-015 an E1B gene attenuated adenovirus, causes tumor especific cytolysis and antitumoral efficacy that can be augmented by standard chemotherapeutic agents. Nat. Med 1997; 3, 639-645.

2. Rogulski KR, Freytag SO, Zhang K, et al. In vivo antitumor activity of ONYX-015 is influenced by p53 status and is augmented by radiotherapy. Cancer Res. 2000; 60: 11931196.

3. Weichselbaum RR, Kufe DW, Hellman S, et al. Radiationinduced tumour necrosis factor-alpha expression: Clinical application of transcriptional and physical targeting of gene therapy. Lancet Oncol. 2002; 3: 665-671.

4. Hallahan D, Mauceri H, Seung L, et al. Spatial and temporal control of gene therapy using ionizing radiation. Nat. Med. 1995; 1: 786-791.

5. Park JO, Lopez CA, Gupta VK, et al. Transcriptional control of viral gene therapy by cisplatin. J. Clin Invest. 2002; 110: 403-410.

6. Staba MJ, Mauceri HJ, Kufe DW, Hallahan DE, Weichselbaum RR. Adenoviral TNF-alpha gene therapy and radiation damage tumor vasculature in a human malignant glioma xenograft. Gene Ther. 1980; 5: 293-300

7. Shariat J.F, Desai S, Song W, et al. Adenovirus-mediated transfer of inducible caspases: a novel "death-switch" gene therapeutic approach to prostate cáncer. Cáncer Research. 2001; 61 (6): 2562-2571.

8. Ikeola H, Nakamura Y, Hiwasa T. Interleukin-1 B converting enzyme (ICE) is preferentially expressed in neuroblastomas with favourable prognosis. Eur. J. Cáncer. 1997; 33(12). 2081-2083. 


\section{G. Vassaux y cols.}

9. Stoetzer OJ, Nussler V, Darsow M, et al. Association of bcl-2, bax, bcl-xL and interleukin-1 beta-converting enzyme expression with initial response to chemotherapy in acute myeloid leukemia. Leukemia. 10 Suppl. 1996; 3: S18-S22.

10. Martin-Duque PM, Quintanilla I, Mc Neish, et al. Caspase1 as a radio- chemo-sensitiser in vitro and in vivo. Submited for International J Cancer. 2005.

11. Samuelson AV, Lowe SW. Selective induction of p53and chemosensitivity in $\mathrm{pRb}$ deficient cells by E1a mutants unable to bind the Rb related proteins. Proc. Natl. Acad. Sci. USA. 1997; 59; 12094-12099.

12. Nelson-Chau B, Lobo-Borges H, Chen T-T, Masselli A, Hunton IC, Wang JYJ. Signal-dependent protection from apoptosis in mice expressing caspase-resistant Rb.Nature Cell Biology. 2002; 4; 757-765.

13. Cook JL, Walker TA, Worthen GS, Radke JR. Role of E1a Rb-binding domain in repression of the NF-kappa B-dependent defense against tumor necrosis factor-alpha. Proc. Natl. Acad. Sci. USA. 2002; 99 (15): 9966-9971.

14. Frisch SM, Dolter KE. Adenovirus E1a-mediated tumor suppression by a c-erbB2/neu independent mechanism. Cáncer research. 1995; 55, 5551-5555.

15. Sanchez-Prieto R, Lleonart M, Ramon y Cajal S. Lack of correlation between p53protein level and sensitivity of DNA-damaging agents in keratinocytes carrying adenovirus E1a mutants. Oncogene. 1995; 11, 675-682.

16. Guinea-Viniegra J, Hernández-Losa J, Sánchez-Arévalo VJ, et al. Modulation of PI3/Akt pathway by E1a mediates sensitivity to cisplatin. Oncogene. Oct 10;21(46):7131-6.

17. He TC, Zhou S, da Costa LT, et al. A simplified system for generating recombinant adenoviruses. Proc Natl Acad Sci U S A. 1998; 95:2509-2514.

18. McNeish IA, Tenev T, Bell S, et al. Herpes simplex virus thymidine kinase/ganciclovir-induced cell death is enhanced by co-expression of caspase-3 in ovarian carcinoma cells. Cancer Gene Ther. 2002; 8: 308-319.

19. Martin-Duque P, Jezzard J, Kaftansis L, et al. Direct comparison of the insulating properties of two genetic elements in an adenoviral vector containing two different expression cassettes. Hum Gene Ther. 2004; 15: 995-1002.

20. Shi L, Chen G, MacDonald G, et al. Activation of an interleukin 1 converting enzyme-dependent apoptosis pathway by granzyme B. Proc Natl Acad Sci U S A. 1996; 93(20): 11002-11007

21. Winter RN, Kramer A, Borkowski A, et al. Loss of caspase-1 and caspase-3 protein expression in human prostate cancer. Cancer Res. 2001; 61:1227-1232.

22. Ramadani M, Gansauge F, Schlosser S, et al. Overexpression of caspase-1 in pancreatic disorders: implications for a function besides apoptosis. J Gastrointest Surg. 2001; $5: 352-358$

23. Nakagawara A, Nakamura $Y$, Ikeda $H$, et al. High levels of expression and nuclear localization of interleukin-1 beta converting enzyme (ICE) and CPP32 in favorable human neuroblastomas. Cancer Res. 1997; 57:4578-4584.

24. Ikeda H, Nakamura $\mathrm{Y}$, Hiwasa $\mathrm{T}$, et al. Interleukin-1 beta converting enzyme (ICE) is preferentially expressed in neuroblastomas with favourable prognosis. Eur J Cancer. 1997; 33:2081-2083.

25. Holzer G, Trieb K, Koschat M, et al. Serum concentrations of APO-1/Fas and interleukin-1beta-converting enzyme in osteosarcoma correlate with response to chemotherapy. Anticancer Res. 2002; 22:1869-1872.

26. Ehrmann J, Jr., Rihakova P, Hlobilkova A, Kala M, Kolar Z. The expression of apoptosis-related proteins and the apoptotic rate in glial tumors of the brain. Neoplasma. 2000; 47:151-155.

27. Merritt JA, Roth JA, Logothetis CJ. Clinical evaluation of adenoviral-mediated p53 gene transfer: review of INGN 201 studies. Semin Oncol. 2002; 28:105-114

28. Kirsch DG, Kastan MB. Tumor-suppressor p53: implications for tumor development and prognosis. J Clin Oncol. 1998; 16:3158-3168.

29. Sanchez-Prieto R, Quintanilla M, Cano A, et al. Carcinoma cell lines become sensitive to DNA-damaging agents by the expression of the adenovirus E1A gene. Oncogene. 1996; 13:1083-1092.

30. Sanchez-Prieto R, Quintanilla M, Martin P, et al. In vivo antitumor effect of retrovirus-mediated gene transfer of the adenovirus E1a gene. Cancer Gene Ther. 1998; 5:215-224.

31. Martin-Duque P, Sanchez-Prieto R, Romero J, et al. In vivo radiosensitizing effect of the adenovirus E1A gene in murine and human malignant tumors. Int J Oncol. 1999; 15:1163-1168.

32. Lee JU, Hosotani R, Wada M, et al. Role of Bcl-2 family proteins (Bax, Bcl-2 and $\mathrm{Bcl}-\mathrm{X}$ ) on cellular susceptibility to radiation in pancreatic cancer cells. Eur J Cancer. 1999; 35:1374-1380.

33. van Brussel JP, van Steenbrugge GJ, Romijn JC, et al. Chemosensitivity of prostate cancer cell lines and expression of multidrug resistance-related proteins. Eur J Cancer. 1999; 35:664-671.

34. Chen Y-H, Wang X, Templeton D, Davis RJ, Tan T-H. The role of c-Jun-N-terminal Kinase (JNK) in apoptosis induced by ultraviolet $\mathrm{C}$ and g-radiation. J of Biol. Chemistry. 1996; 271: 31929-31936.

35. McEleny KR, Watson RW, Coffey RN, et al. Inhibitors of apoptosis proteins in prostate cancer cell lines. Prostate. 2002; 51:133-140. 